\title{
PSYCHOLOGICAL AND HEALTH ISSUES FACED BY WOMEN AND THEIR PERCEPTIONS ABOUT PREVENTING MEASURES IN DISTRICT JAIL FAISALABAD, PUNJAB PAKISTAN: A QUALITATIVE STUDY
}

\author{
Asma Ehsan \\ M.Phil Scholar in Sociology, \\ Department of Sociology, Government College University Faisalabad \\ asmaehsan1193@gmail.com \\ Zaib-un-Nisa \\ M.Phil Scholar in Sociology, \\ Department of Sociology, Government College University Faisalabad \\ zaibu0083@gmail.com \\ Uzma Niaz \\ PhD Scholar in Sociology, \\ Department of Sociology, Government College University Faisalabad \\ uzmaniaz360@gmail.com
}

\begin{abstract}
Crime committed by a woman is an important factor that influences the family's harmony and social stability. In recent years, the female crime rate has been a gradual increase, and its growth rate has exceeded that of male crime in the corresponding period. This not only relates to the weakly legal consciousness of a small number of women but also relates with the families and the society. To effectively prevent and control female crime. Efforts should be made to enhance women's legal and moral education, combat domestic violence, perfect the legal system, improve the social security system, and strengthen the assistance and education to female prisoners. This study is designed to investigate the psychological and health issues faced by women who are under lock in the district jail Faisalabad. The study was qualitative and the case study method was used for data collection from the district jail Faisalabad. The present study was conducted in the district jail of Faisalabad. 15 Women were taken as a sample size that is under lock in the district jail Faisalabad. In-depth interviews were conducted with the respondents, to explore their psychological and health issues. Moreover, thematic analysis was applied to draw the results and analysis.
\end{abstract}

Keywords: Psychological, health, women, family's harmony, preventing measures, thematic analysis

\section{INTRODUCTION}

The word Jail is defined as the cells located in a city, or a town, sometimes small lock-up in police stations where people who have been arrested or charged with a crime are held until they are either released or sentenced to prison. (Ronald, 2007). In Pakistan, health facilities are either nonexistent or very few in women's prisons. In most of the raped cases that have become pregnant, they end up delivering a baby while still in jail for a crime not committed. They are badly treated as having no access to pre-natal and post-natal health facilities. The women prisoners are under-nourished and overworked in jail and ultimately pregnant one gives birth to a baby in the unhygienic and poor health care facility. This results in a disproportionately high number of infant and maternal deaths in a country (Rafiq, 2004). Women prisoners are bound to have encountered physical and sexual injury before detainment or even in jail. Prisoners who are mishandled by staff have no chance of getting away from their victimizer. The individuals who record a grumbling or make a legitimate move are in danger of additional retaliatory maltreatment, regardless of whether they are moved to another office (Quinn 2010).

Women who are pregnant on entering prison (or become pregnant during their detainment because of the maltreatments referenced above or of sexual arrangements), just as nursing moms, are needing specific medical services offices which are frequently inaccessible or woefully lacking. The 
youngsters (counting those at this point unborn) of these women additionally require specific thought as far as clinical and dietary necessities. Women who conceive offspring while detained are seldom permitted to invest energy with their youngsters after birth. Mother-baby holding is seriously subverted by this absence of contact after birth. Most remedial frameworks don't consider the significance of the mother-youngster relationship in planning strategy for women in prison. Terminations of parental rights likewise influence prison moms (Porter and Wright, 2003). As well as requiring essential health care, women wrongdoers frequently have explicit health needs identified with their unsafe sexual and medication utilizing conduct preceding imprisonment or in prison.

Women in Jail suffer from many dangerous diseases and some of them are diseases that can easily spread from one to another. These include HIV, TB sexually transmitted diseases (STI), Hepatitis A, B, C infection. In addition, many types of Infections are easily transmitted from one woman to another by using dirty washrooms and other necessities of life. There is a risk of getting infected easily from one woman to another. Pregnancy and care of pregnant women is a very important issue in the health sector that should not be ignored. (Pollock 1986). Pre-natal and postnatal care of a pregnant woman and her baby is also not being done properly, leading to various diseases like women and newborns. And newborns are malnourished. Women are not isolated after birth and their health and hygiene should be taken care of. There are also signs of emotional, physical, and sexual abuse.

There are few studies in Pakistan and neighboring countries especially in Bangladesh who focused on the mental health conditions of prisoners and the conditions of female prisoners are rarely studied. False and fake health certificates are very popular in these countries which cause mental and psychological challenges for a normal person. Such kind of physicians should be punished and further studies were needed to explore the issue (Hussain \& Forrester, 2021). The foremost challenge is anxiety among the women in prison. In addition, health issues are already discussed above. The contact with family is also not easy which contribute negatively in the psychological issues of the prisoner women (Rujiprak, 2021). Sexual harassment at jails is also a reason of emotional and psychological problems (Abid et. al., 2020).

Keeping in view the above situation, this study was designed to explore the different aspects of health problems including mental and physical problems of women prisoners in Faisalabad. Objectives of the study are given below:

Objectives

1. To explore the psychological and health condition of the prisoned women.

2. To identify the availability of health care services in the Jail as well as to assess the utilization of these services.

3. To suggest some recommendations in the light of problems identified during the study.

\section{REVIEW OF LITERATURE}

In 1995, about 10,800 women became pregnant even as in captivity. Due to flow, abortion, miscarriage, prison switch policies, and so on, the variety of stay births in prison became very low (Acoca, 1998). In widespread, pregnant Women are transferred to other Hospitals for childbirth due to the fact their correctional centers aren't medically organized to provide such services. These congenital malformations often cause several clinical and intellectual fitness complications. That is, precautionary measures growth a lady's risk of injury and strain (Young, 1998; Belknap, 2000). In addition, after delivery, women prisoners face the loss of their toddlers. The problem of kids in the back of the backs of imprisoned women is one of the challenges that only a few prisons up to now allow newborns to stay with their mothers and rather they're normally rushed to family or foster care or right away after delivery (American Correctional Association, 2000; Belknap, 2000).

Tosh, (1982) found that these comprise of powerlessness and despairing, actual mischief, disturbance of social connections, self-damage, self-destruction, and mental disease, just as developing troubles in acclimating to life after dispatch. The most material alterations to lessen jail misuse incorporate developing gathering of laborers and assurance, receiving unit the executives, and diminishing imprisonment rates.

Prison suicide is the effect of psychological issues. Bartol and Bartol, (1994) discussed the event of jail self-destruction as proof that jail life is unpleasant to numerous detainees. In 1981, Bart ollas recommended three significant explanations behind jail self-destruction. These incorporate 
prisoners who were humiliated by the disrespect they have brought upon their families and discover their blame and corrupted confidence unfortunate; found that the feeling of powerlessness and absence of command over their carries on with was deplorable. The result of psychological destruction was that prisoners were taking their lives.

Fatima Bilal (2011) studied the psychological issues of women prisoners and showed a substantially high psychiatric morbidity among female inmates. The disorders included depressive illnesses, stress-related disorders, somatoform disorders, psychotic disorders, and organic mental disorders.

Avais (2020) studied the challenges of female prisoners in Sindh, Pakistan; the province which is even neglected in national studies. The health of women prisoners was found more susceptible in comparison to men. In total, 113 respondents (female prisons in Sindh) were interviewed in three big cities of Sindh. Among them, 28 were convicted and 85 were under trial: 85 . Education showed a positive relationship towards their health in prison. They found it a challenging task for the local, provisional and national governments to provide adequate health facilities for females in prison. Specific health issues regarding females were not considered very well.

Zakir et. al., (2020) studied the health issues of female prisoners and considered national and international laws about their rights. In December 2020, ten years were passed to Bangkok rules in favor of women prisoners' health. They considered the gender needs of women, their psychological and physical health as well as emotional needs. Malnutrition is a big challenge for women in prison as well as urine effect among intimate disease is found common among them which are directly related to their psychological problems. They suggested that the Bangkok rules should be followed by countries as much as possible.

Abid et. al., (2020) studied women's sexual harassment experiences in prisons. Their results showed that the majority of the women faced a medium level of gender and sexual harassment. They found it difficult to interview them in jails and explored those experiences of sexual harassment and noted that these experiences became the reason for emotional and psychological problems. Hussain \& Forrester (2021) reviewed the mental health conditions of prisoners in Bangladesh. They found that there was a lack of studies on this topic. With mental health conditions, they discussed one important point that can be expected in the context of Asian country and that is false or fake health certificates which can also be the cause of mental issues for a normal person. Such kinds of physicians should be punished and further studies were needed to explore the issue. Rujiprak (2021) studied the life experiences of imprisoned women in Thai jails with a large sample of 2,499 women who were imprisoned in 20 jails in Thailand. The results disclose that the foremost challenges were anxiety and the wish and need for companionship. In addition, health issues were also explored and social contact with family was also challenging to maintain.

\section{RESEARCH METHODOLOGY}

This research was completed in the district jail situated in Jail Road, Faisalabad, Punjab Pakistan. The researcher adopted a qualitative research design with the case study approach. Qualitative data were collected using face-to-face interviews with the help of an interview guide which was developed for data collection. Thematic-content analysis was applied to draw the analysis, results, and conclusions. The total imprisoned women in the district jail Faisalabad was 92. The researcher took a sample of 15 prisoners as respondents out of 92, they all were convicted. The study is based on primary data and primary data were collected through face-to-face interviews. The researcher has collected this data in 8 days by herself from 6-2-2020 to 13-2-2020 with the permission of the competent authorities and the anonymity of the respondents was assured at the time of the interview under ethical consideration as the topic was sensitive. After data collection, the researcher dissected the data and shaped contextual analyses dependent on singular cases.

\section{RESULTS AND DISCUSSIONS}

\section{Theme 1: Determinants of Engaging in Criminal Activity}

At first, the researcher asked about the reasons behind their criminal act. The majority of the females were not admitting that they did any crime and they said that they are innocent. Few of them admitted that they commit the crime. The common reasons behind their action were underage marriage, negative popularity, domestic violence, and self-defense as they did not intend but in self-defense, the 
crime was committed. In these cases, analyses have proven that socially disorganized ideology inlining crime with ladies is a solid ideology, as ladies face some detrimental situations together with pressured and underage marriage, negative popularity, housing and community, and age element in the societies from which they commit crimes. Lack of formal schooling has been another predominant issue in these fifteen cases, as most women did not even pass their secondary school examination. Poverty and unemployment and domestic violence were other important factor. One of the women stated that "she has no role model in her life to follow or no one to let her know about the difference of right and wrong, eventually this happened".

\section{Theme 2: Provision of Medical Facilities for Prisoner}

The results based on the thematic content analysis indicate that some prisoners were not medically examined at the time of entry by the jail administration. Some of them were examined at the time of their entry into prison. This will have a positive effect on the prison authority if they follow the rules of medical examination at the time of their arrival in Jail or prison. This examination can save the jail administration as well as the other prisoners in jail. As the data was collecting during the Covid-19 period so the people were afraid of such kinds of diseases and interaction with each other. The study also finds that there was no appropriate medical treatment for the pregnant mothers and nursing mothers with inadequate nutrition, low quality of prenatal care, and postnatal care which affects their health. In the self-reporting, the female prisoners do let the researcher know about their diseases including Hepatitis C, Hepatitis B, diabetes, hypertension, and joint pain are the most common diseases in women. They need proper medication and diet but the women in prison are not given proper medication or diet which is making them weaker day by day. Regular medication is needed in case of certain diseases like hypertension, hepatitis, and diabetics but it is not provided to them. Overall, the hygienic conditions were not satisfied that was becoming the reason for urine infection and other intimate diseases. There is no privacy for the newborn child and the mother which causes serious physical and psychological issues.

\section{Theme 3: Psychological Health Challenges of Prisoners}

With the physical diseases, they were facing psychological challenges as well that are more critical to address. The Psychological disease that they reported were tension, stress, mental illness, and muscle pull due to tension are the most common diseases in women. The researcher observed that they were better aware of their physical diseases in comparison to psychological issues. They were afraid of their future and especially the mothers with children were very much worried about their social integration after they left the jail. One of the mothers said that "I am not afraid for myself but I am afraid that society will not accept my children with respect even not my family". Those who have their children at home stated that it is difficult for them to stay without their children. This separation from family and especially from the children makes them psychologically upset. The family remained the foremost reason for their continuous mental illness.

There were no frequent sessions with the psychiatrists for these females. As a result of these psychological problems, they often start quarreling with other prisoners in jail. The only way to stop and control them is the use of force and verbal abuse from the side of jail staff which is pushing them in more stress and disgrace.

It was analyzed that many women in prison are treated very inappropriately by the jail authority that is why they may be tormented by many intellectual ailments together with pressure, tension, and anxiety disorders. They are suffering from anxiety. Personality sickness, psychological problems (along with schizophrenia), and eating and sleeping disorders were reported. Most respondents agreed that after completing their punishment, they will go back home after release but they were not sure about their acceptance in society.

\section{CONCLUSION}

This is a very straightforward and categorical conclusion drawn from this study that in jails the separation of parents from their children has caused many problems in their lives. Separation from children as well as family members is the biggest cause of pain for women. In addition, pregnant women and their newborns face many problems while incarcerated, because these women are not kept separate from other women, nor are they properly cared for and fed properly, which causes many 
serious problems for both the baby and the mother. This Causes many mental problems in women which are usually lack of sleep, tension, brain stress, anxiety, high blood pressure, and many physical problems. One of the most common issues for women prisoners in the absence of privacy. The women in jail are not given proper remedy or food that's making them weaker on daily basis. Mentally ill patients are victims of abuse and feature a complicated set of human rights safety needs, along with the provision of adequate mental health care. In addition, they are no longer being aware of their jail rights. However, according to the women in Faisalabad District Jail, the institution has made drastic reforms for them, Special care is taken for cleanliness in the institution, the absence of odors in residential units, and the provision of clean water is also very important, in addition, various vocational courses are conducted for the betterment of women so that women can be kept busy and make them skilled.

\section{RECOMMENDATIONS}

1. Lab tests should be completed at the time of entry so that other persons can be saving from getting infected. In general, the gynecological issues of women should be addressed, and specifically, the issue of mother and newborn child should be considered and solved. Medical and other issues like food, water, and hygiene should be solved. Mealtimes should be changed. Pregnant and lactating women should be fed four to five times a day instead of three.

2. There should be awareness sessions regarding the psychological issues of the women as well as about the understanding of their legal rights. Separate seminars should be organized for women suffering from depression, mental problems, and sleeping disorders, they should be provided with a variety of treatments.

3. Government should solve the issue of overcrowding in jails and keep the women in separate cells according to their type of crime. Their privacy should be maintained as per the rules of human rights which can have a good effect on the physical and mental health of the women in prisons.

4. The posts of Dentist, Physiotherapist, and Psychologist should be created and the approved posts should be done on an immediate basis

\section{REFERENCES}

Abid, M., Riaz, S., Khalid, M., \& Iqbal, R. (2020). Sexual Harassment Experiences of Female Prisoners in Jail. Pakistan Journal of Psychological Research, 73-85.

Avais, M., Wassan, A., \& Narijo, H. (2021). Female Prisoners in Sindh: A Health Analysis for Policy Makers. sjesr, 4(2), 477-482.

Acoca, L. (1998). Diffusing the Time Bomb: understanding and Meeting the Growing Health Care Needs of Incarcerated Women in America Crime and delinquency; 44 (1), 49-70.

American Correctional Association. (2000). Inmate health care-Part 2. Corrections Compendium, (11), 1-35.

Bartol, C.R., and Bartol, A.M. (1994). Psychology and Law: Research and Application (2nd ed.). Pacific Grove, CA: Brooks/Cole.

Belknap, J. (2000). The Invisible Woman: Gender, Crime, and Justice (2nd ed.). Belmont, CA: Wadsworth.

Bilal, F., \& Saeed, K. (2011). Psychiatric morbidity among the female inmates of district jail Adyala, Rawalpindi. Rawal Medical Journal, 36(2), 129-+.

Hussain, A., \& Forrester, A. (2021). Mental health services in the prisons of Bangladesh. Published by Cambridge University Press, pp. 1-4 doi:10.1192/bji.2021.34

Rafiq, S. (2004) Justice and Equality for Women, Pak Tribune, website: www.paktribune.com.

Porter, R \& Wright, D (eds.) (2003). The Confinement of the Insane: International Perspectives, Cambridge, England: Cambridge University Press.

Quinn, A. R. (2010). Can't Do It on My Own: When Women Go to Prison. Vandalia, Missouri.

Rujiprak, V., Limprasert, S., \& Thipphayamongkoludom, Y. (2021). A quantitative analysis of common challenges faced by women prisoners in Thai prisons. Social Science Asia, 7(3), 6780.

Tosh, J. (1982). The Pains of Imprisonment. California: Sage Publications. 
Young, D. (1998). Health Status and Service use Among Incarcerated Women. Family Community Health, 21(3), 16-31.

Zakir, S., Khan, M. A., \& Feroz, S. (2020). Right to Health of Female Prisoners: A Critical Analysis of KP Prison Act in the Light of International Human Rights Law. Global Legal Studies Review, V(III), 21-32. https://doi.org/10.31703/glsr.2020(V-III).03 